\title{
A IMPLANTAÇÃO DA TERAPIA COMUNITÁRIA INTEGRATIVA EM UM MUNICÍPIO DO RIO DE JANEIRO
}

\author{
LA IMPLEMENTACIÓN DE LA TERAPIA COMUNITÁRIA INTEGRATIVA EM UM \\ MUNICÍPIO DE RIO DE JANEIRO
}

\author{
THE IMPLEMENTATION OF INTEGRATIVE COMMUNITY THERAPY IN A \\ MUNICIALITY IN RIO DE JANEIRO
}

\author{
Erika MACEDO ${ }^{1}$ \\ Vera Lucia LUIZA ${ }^{2}$ \\ Vera Cecília FROSSARD ${ }^{3}$
}

RESUMO: Objetiva-se aqui descrever e analisar o processo de implantação da Terapia Comunitária Integrativa (TCI) em Volta Redonda, município do Rio de Janeiro. Utilizou-se entrevista semiestruturada e observação das Rodas de TCI no período de setembro-novembro de 2019, além de análise documental. Nos documentos municipais, a TCI começou a ser referenciada a partir de 2009 até o momento atual (2018 a 2021), passando a ser prevista no Projeto Centro de Práticas Integrativas da Secretaria Municipal de Saúde. A análise de implantação revelou a importância do contexto político, ora como facilitador da implantação, ora como barreira para manutenção de sua oferta. Apesar da mudança do contexto político ter ocasionado a diminuição da oferta de rodas de TCI, houve o reconhecimento do seu potencial na construção de redes de apoio social assim como na atenção às demandas de saúde mental, como por exemplo, a redução da medicalização.

PALAVRAS-CHAVES: Terapia comunitária integrativa. Saúde mental. Análise de implantação. Práticas integrativas e complementares em saúde.

RESUMEN: El objetivo aquí es describir y analizar el proceso de implementación de la Terapia Comunitaria Integrativa (TCI) en Volta Redonda, municipio de Rio de Janeiro. Se utilizaron entrevistas semiestructuradas y observación de las ruedas de las TCI de septiembre a noviembre de 2019, además del análisis documental. En documentos municipales, TCI comenzó a ser referenciado desde 2009 hasta el momento presente (2018 a 2021), comenzando a preverse en el Proyecto del Centro de Prácticas Integrativas de la Secretaría Municipal de Salud. El análisis de implementación reveló la importancia del contexto político, a veces como un facilitador de la implantación, a veces como una barrera para mantener su oferta. A pesar

\footnotetext{
${ }^{1}$ Escola Nacional de Saúde Pública Sergio Arouca, Fundação Oswaldo Cruz (ENSP/Fiocruz), Rio de Janeiro - RJ - Brasil. Mestranda no Programa de Pós-Graduação em Saúde Pública. ORCID: https://orcid.org/0000-00019486-1853. E-mail: erikamacedo@globo.com

${ }^{2}$ Escola Nacional de Saúde Pública Sergio Arouca, Fundação Oswaldo Cruz (ENSP/Fiocruz), Rio de Janeiro - RJ - Brasil. Pesquisadora em Saúde Pública. Doutorado em Saúde Pública (ENSP/Fiocruz). ORCID: https://orcid.org/0000-0001-6245-7522. E-mail: negritudesenior@gmail.com

${ }^{3}$ Escola Nacional de Saúde Pública Sergio Arouca, Fundação Oswaldo Cruz (ENSP/Fiocruz), Rio de Janeiro - RJ - Brasil. Pesquisadora em Saúde Pública e Atenção Primária no Centro de Saúde Escola Germano Sinval Faria. Doutorado em Bioética, Ética Aplicada e Saúde Coletiva (UFRJ/RJ). ORCID: https://orcid.org/0000-0002-34919619. E-mail: verafrossard@ensp.fiocruz.br
} 
del cambio en el contexto político que condujo a una disminución en el suministro de ruedas de las TIC, se reconoció su potencial para construir redes de apoyo social y para atender las demandas de salud mental, como reducir la medicalización.

PALABRAS CLAVE: Terapia comunitaria integradora. Salud mental. Análisis de despliegue. Prácticas integrales y complementarias de salud.

ABSTRACT: The objective is to describe and analyze the implantation process of integrative community therapy (ICT) in Volta Redonda, municipality of Rio de Janeiro. Semi-structured interviews and observation of ICT groups were carried out, during the period of September to November, in addition the occurrence of documentary analysis. In municipal documents, ICT began to be referenced since 2009 until the present moment (2018 to 2021), starting to be foreseen in the Project Center for Integrative Practices of the Municipal Health Department (Secretaria Municipal de Saúde). The implementation analysis revealed the importance of the political context, sometimes as a facilitator agent of implementation, and sometimes as a barrier to maintaining its offer. Despite the change in the political context becoming a factor that decreased the number of groups of ICT, there was recognition of its potential in the construction of social support networks, as well as in the attention to the demands of mental health, such as, for example, the reduction of medicalization.

KEYWORDS: Integrative community therapy. Mental health. Analysis of implementation. Integrative and complementary health practices.

\section{Introdução}

A pós-modernidade vem trazendo mudanças no modo de vida das pessoas. De um lado, assistimos um maior acesso aos bens e serviços produzidos pela sociedade e, de outro, verificamos que a desigualdade - como um fenômeno socioeconômico - e a exclusão - como um fenômeno cultural e social - se tornam muito mais presentes nas sociedades capitalistas, manifestando-se através da precarização geral do trabalho, do aumento da criminalidade, do abuso de drogas, da violência social e da miséria.

Este processo é majoritariamente marcado por situações de sofrimento, muitas vezes expresso por meio de queixas somáticas inespecíficas como: dores de cabeça e no corpo, insônia, nervosismo, problemas gástricos, estado de mal-estar, dentre outros. Esses são exemplos de sintomas que não apresentam causas orgânicas específicas. Assim, não são facilmente classificáveis nos diagnósticos médicos e psiquiátricos, porém têm íntima relação com fatores psíquicos e sociais. Este tipo de sofrimento foi nomeado pelo pesquisador Victor Vincent Valla (2001) como sofrimento difuso e colocado como uma das maiores demandas de atenção em saúde nas classes populares. 
Entre as queixas somáticas inespecíficas, ainda podemos encontrar o diagnóstico de Transtornos Mentais Comuns (TMC), que podem se apresentar através de múltiplos sintomas, tais como queixas somáticas inespecíficas, irritabilidade, insônia, nervosismo, dores de cabeça, fadiga, esquecimento, falta de concentração, além de manifestações que podem se caracterizar como sintomas depressivos, ansiosos ou somatoformes (FONSECA; GUIMARÃES; VASCONCELOS, 2008).

Como se apresentam principalmente através de queixas somáticas inespecíficas, a prevalência dos TMC na atenção básica é alta, por ser esta também a porta de entrada dos serviços de saúde. Porém, havendo um enfoque na queixa imediata dos usuários, sem o reconhecimento do mal-estar mais amplo, implicará em gastos com encaminhamentos e exames desnecessários.

A implementação de uma prática grupal, de origem brasileira, chamada de Terapia Comunitária Integrativa (TCI), implantada na atenção básica no Sistema Único de Saúde, pode ser uma proposta de acolhimento das situações de sofrimento, possibilitando a problematização de questões coletivas, o fortalecimento das redes de apoio social, espaço de escuta, vínculo e desmedicalização da vida (FONSECA; GUIMARÃES; VASCONCELOS, 2008)

Desenvolvida no Ceará em 1987, a TCI vem emergindo como política pública em tecnologia de cuidado e estratégia de fortalecimento do modelo comunitário na Atenção Primária em Saúde. Compõe desde 2017 o conjunto de Práticas Integrativas e Complementares em Saúde (PICS), da Política Nacional de Práticas Integrativas e Complementares (PNPICS) (BRASIL, 2006; 2017).

A municipalização decorrente da descentralização do sistema Único de Saúde (SUS), fez do município o principal espaço para implementar as políticas de saúde, tendo cada um seu próprio cenário local que vai influenciar na implantação e na efetividade das intervenções.

Considerando a TCI como parte da PNPIC, a realização deste estudo é pertinente por se propor analisar o processo de implantação desta intervenção no município citado, permitindo identificar os desafios de implementação em diferentes Unidades de Atenção Básica de Saúde. Além deste fato, se torna relevante, na saúde coletiva, avaliar práticas com a intenção de verificar sua competência reconhecida e compatibilidade com os princípios norteadores do SUS: universalidade, integralidade e equidade. 


\section{Material e métodos}

A pesquisa no município se deu por meio da análise qualitativa do processo de implantação; que é um procedimento científico que valoriza o contexto onde a intervenção estudada está inserida (CHAMPAGNE et al., 2011).

\section{Contexto do estudo}

A cidade de Volta Redonda é um dos principais municípios do Estado do Rio de Janeiro, região Sudeste do Brasil. Com uma população estimada em 2019 de 273 mil habitantes e Índice de Desenvolvimento Humano Municipal (IDHM) de 0,771(2010), possui uma área de 182,105 $\mathrm{km}^{2}$, apresentando importância significativa para a economia regional e estadual (IBGE, 2010), tendo o município papel fundamental na história do desenvolvimento industrial do Brasil (MAGALHÃES et al., 2012).

Embora a história do município tenha referências no século XIX, o grande marco está na década de 40, do século passado, quando foi criada a Companhia Siderúrgica Nacional (CSN), quando tem início o processo de industrialização do país, o que implicou em desenvolvimento diferenciado dos demais municípios. Abrigando a maior usina siderúrgica da América Latina é conhecida como a "Cidade do Aço" e o crescimento da cidade deu-se em torno da CSN, que representou para a população residente, durante muitos anos, o grande mercado de trabalho da cidade (PINTO et al., 2012).

A privatização da CSN, em 1993, constituiu-se em um marco divisor, desencadeando novas situações e novos desafios para a cidade, inclusive no campo da saúde. Esse cenário permitiu que o poder público assumisse seu papel de gestor da saúde através da expansão e fortalecimento das unidades de saúde de caráter público, invertendo a lógica do modelo curativo até então vigente (PINTO et al., 2012).

A Rede de Atenção em Saúde (RAS) do município de VR é uma das mais complexas e completas da região do Médio Paraíba, sendo, por isto mesmo, referência regional para população de muitas cidades (PINTO et al., 2012).

\section{Aspectos operacionais}

Foram coletados dados primários por meio de entrevistas semiestruturadas de base dialógica, contendo questões temáticas norteadoras e a observação do contexto das Rodas de TCI. Complementarmente, foram analisados documentos da Secretaria Municipal de saúde 
como: o Plano Municipal de Saúde, a Programação Anual de Saúde, os Relatórios Anuais de Saúde e os Relatórios das Conferências de Saúde.

O cenário da avaliação foram as rodas de TCI realizadas em duas Academias da Saúde e outra no Zoológico Municipal, local onde a prática foi iniciada no município. O material empírico foi produzido a partir de dados documentais, entrevistas semiestruturadas e observação às rodas de TCI. Foram entrevistados três gestores, quatro terapeutas comunitários, nove profissionais que trabalhavam nas Academias de Saúde e nas Unidades de Saúde e nove usuários participantes das rodas. As entrevistas semiestruturadas foram gravadas e posteriormente transcritas.

Nos Planos Municipais (2008/2010; 2011/2013, 2014/2017 e 2018/2021), na Programação Anual de Saúde (2014, 2015, 2016 e 2017) e no Relatório Anual de Gestão (2009 a 2019), buscou-se identificar como se inserem as PICs, se há referências específicas à TCI e o que se prevê quanto a ela.

\section{Análise dos dados}

As informações obtidas por meio de documentos, entrevistas e observação foram submetidas à análise do conteúdo temática categorial, sugerida por Bardin (2011). Esta técnica foi dividida em três fases: A pré-análise; a exploração do conteúdo; e o tratamento dos resultados, inferência e interpretação.

Com base nos objetivos do estudo e a partir da Análise de Conteúdo temática categorial (BARDIN, 2011) foram obtidas duas categorias: Implantação e Intervenção, para as quais foram identificadas subcategorias.

Quadro 1 - Categorias e subcategorias identificadas nas falas

\begin{tabular}{|l|l|}
\hline Categorias & Subcategorais \\
\hline \multirow{4}{*}{ Implantação } & Contexto \\
\cline { 2 - 2 } & Facilitadores \\
\cline { 2 - 2 } & Barreiras \\
\hline \multirow{4}{*}{ Intervenção } & Oferta Inicial \\
\cline { 2 - 2 } & Oferta atual \\
\cline { 2 - 2 } & Barreiras para Manutenção da Oferta \\
\cline { 2 - 2 } & Percepções sobre a Efetividade \\
\hline
\end{tabular}

Fonte: elaborado pelos autores 


\section{Cuidados éticos}

O projeto foi aprovado por Comitê de Ética em Pesquisa e as entrevistas foram conduzidas após assinatura de termo de consentimento livre e esclarecido. Obteve-se anuência formal para a realização das entrevistas.

\section{Resultados}

Participaram das entrevistas semiestruturadas 25 pessoas: 3 gestores, 4 terapeutas comunitários, 9 profissionais das UBS e 9 usuários participantes das rodas de TCI. Dentre os gestores, 2 atuavam na Secretaria Municipal de Saúde e uma encontrava-se aposentada. Os terapeutas comunitários, atuantes nas rodas oferecidas pelo Município foram: duas terapeutas na Academia de Saúde de Nova Brasília e outras duas no Zoológico Municipal e na Academia da Saúde de Volta Grande. Dos profissionais que se dispuseram a dar entrevistas, pudemos contar com dois profissionais da Unidade Básica de Saúde da Família (UBSF) de Nova Brasília, um profissional da Academia da Saúde de Nova Brasília; três profissionais do Caps Nova Esperança; dois profissionais da UBSF de Volta Grande e uma profissional da Academia da Saúde de Volta Grande. Dentre os participantes das rodas, foram escolhidos três de cada local.

Dentre os entrevistados, 23 eram do sexo feminino e 2 do sexo masculino, com idades que variaram de 22 a 66 anos. As entrevistas com os gestores foram previamente agendadas; com os terapeutas, profissionais e usuários participantes das rodas, foram realizadas após a observação, nos dias de roda de Terapia Comunitária. Apenas um profissional foi entrevistado com hora marcada, pela impossibilidade de horário no dia da observação das Rodas. Todas as entrevistas foram gravadas e posteriormente transcritas. Em meio a este processo 1 entrevista com um usuário foi perdida, por falha na gravação.

\section{Implantação: Momento Inicial}

A triangulação das informações captadas nas entrevistas e documentos da SMS-VR levou a identificar o período 2008 até 2014 como o momento de implantação. Os documentos da Secretaria de saúde referem-se à implantação da TCI em vários momentos deste período, considerando-a como meta alcançada. O período posterior foi considerado como da intervenção e, como se verá mais adiante, foi caracterizado por momentos de ampliação seguido por momento de maiores dificuldades, o que perdura até hoje. 
Durante esse período de implantação foram realizadas três capacitações $(2008,2011$ e 2013), somando um total de 25 profissionais formados.

A decisão de implantar a técnica no município de Volta Redonda surgiu a partir da Capacitação em TCI da primeira turma de 2008, pelo Ministério da Saúde, após um primeiro contato de uma gestora da SMS de Volta Redonda com a técnica, em um Congresso de Medicina de Família e Comunidade.

Então, após o Congresso, a Secretaria Municipal de Volta Redonda, assim como outras secretarias, foi indicada pela então Secretaria de Estado de Saúde e Defesa Civil (Sesdec/RJ) para realizar a capacitação de um grupo de profissionais. Foi nesse momento que a Coordenação de Programas e Projetos da Secretaria Municipal de Saúde do município de Volta Redonda, indica o nome de 10 profissionais de saúde da SMS/VR para processo seletivo. Dentre esses profissionais, 8 foram selecionados para participarem do I Curso de Formação de Terapia Comunitária Sistêmica Integrativa no SUS do Estado do Rio de Janeiro, que teve seu início em agosto de 2008 e encerramento em fevereiro de 2009, em Guapimirim (RJ). A Secretaria Municipal de Saúde indicou profissionais da saúde: médicos, dentistas, fisioterapeutas e Agentes Comunitários de Saúde.

A partir deste momento, outras duas edições de formação em Terapia Comunitária foram realizadas através das atividades de Educação Permanente do Polo-Sul-RJ: uma realizada no ano de 2011 e outra no ano de 2013, em Arrozal (RJ). No total foram capacitados 25 profissionais de saúde em Terapia Comunitária no município de Volta Redonda. Dentre esses profissionais, alguns possuíam vínculo empregatício estável (concursados) e outros vínculo empregatício mais instável (contratados).

Segundo informações coletadas nas entrevistas com gestores, a seleção para a capacitação em TCI priorizava o perfil dos profissionais e não o vínculo de trabalho. Com isso, na primeira turma de 2008 , de oito profissionais, cinco eram servidores públicos. Na turma de 2011 de cinco profissionais, apenas um era servidor público. E na turma de 2013, de 12 profissionais apenas um era servidor público. De um total de 25 terapeutas formados, apenas sete possuíam vínculo empregatício estável.

A primeira roda de Terapia Comunitária Integrativa foi realizada no Horto Municipal, sendo realizada semanalmente até o presente momento. Após a primeira turma formada em TCI, o Município contou com quase 16 rodas semanais espalhadas por diferentes pontos da cidade, e chegaram a possuir uma equipe mínima de três terapeutas para rodas de TCI (Os terapeutas tinham sua agenda exclusiva para TCI). Talvez esse tenha sido o ápice da implantação da TCI no Município. 
Assim, dentre os aspectos facilitadores da implantação, o apoio da gestão central do município foi, claramente nesse sentido, garantindo infraestrutura, recursos humanos e outras condições, como expresso por duas gestoras.

A única barreira sinalizada, por apenas uma entrevistada da gestão, foi a resistência inicial tanto da equipe de saúde quanto dos usuários em função do desconhecimento sobre a nova intervenção. Como estratégia de implantação foi necessário realizar sensibilização dos usuários e da equipe de saúde para a nova técnica em implantação, o que se deu em especial no Conselho Municipal de Saúde. O estranhamento se deu pelo fato de a condução não estar atrelada à formação em psicologia, havendo resistência por parte das equipes. A estratégia foi então iniciar a oferta da TCI fora do espaço das unidades de saúde.

Nos documentos da SMS, no momento inicial, a implantação é programada no PMS 2011-2013. Na PAS de 2014, a Implantação da TCI é encontrada como ação proposta e executada em um Território. Nos RAGs, a implantação da TCI em várias unidades e equipes, aparece dentre as ações desenvolvidas e encontrada fazendo parte das ações do Programa de PICS, juntamente com a homeopatia e a fitoterapia.

\section{Intervenção}

Nesta categoria são abordados aspectos da organização da intervenção, tanto no início quanto no momento atual. A implantação da TCI contou com a oferta inicial de um grande número de rodas em diferentes territórios da cidade.

Quanto à oferta atual, baseado na descrição da oferta atual e nas entrevistas, houve uma redução de mais de $80 \%$ da oferta.

Como Barreiras para continuidade da Oferta foi relatado que a mudança de governo, acarretou mudanças também na política e nas prioridades da gestão. Algumas demissões foram sendo realizadas e dentre estas constavam as de muitos terapeutas comunitários, o que fez a oferta da TCI ser reduzida pela falta de profissionais capacitados na técnica.

Ainda que reconhecendo as demissões como um problema, a mudança de prioridades políticas também pode indicar o atual como um momento político menos favorável à técnica.

Onze anos depois da implantação da TCI, as entrevistas apontaram para a necessidade de uma luta para permanência da oferta da intervenção. Acredita-se que a resistência da intervenção se deu em virtude da existência de terapeutas comunitários na gestão central ainda nos dias de hoje e da solicitação da comunidade pela sua permanência: 
Quanto às percepções sobre a efetividade da técnica entre os terapeutas comunitários, foram mencionadas mudanças concretas nos comportamentos dos usuários, com ganho de autoconfiança, redução de medicamentos utilizados, e da necessidade de atendimentos especializados. O reconhecimento como uma estratégia terapêutica na saúde mental e a valorização do saber popular foi também percebida por um terapeuta comunitário; o que sinaliza um potencial da TCI na atenção às demandas de saúde mental com redução da medicalização. O espaço de escuta e ajuda mútua por si foi resolutivo para algumas demandas, prevenindo que se medicalizasse o sofrimento.

Entre os profissionais das UBSF a maioria vê a TCI como efetiva, uma técnica potente e todos mencionaram fazer indicação para a roda. Um profissional mencionou a redução de medicamentos, outro o combate à depressão e um terceiro a possibilidade ao usuário conquistar autonomia e como um espaço de socialização e troca de experiências.

Apenas uma profissional, que nunca participou de uma roda (somente a conhece na teoria e de ouvir o retorno dos usuários) referiu, apesar de vê-la como recurso importante, que lhe chama a atenção o fato de alguns usuários que retornaram dizendo não terem se adaptado. Ao ser perguntada sobre o motivo, foi mencionada a questão de o trabalho coletivo incomodar alguns usuários.

Outras menções por diferentes usuários incluíram: a importância do aprendizado (relato pelo usuário com pouca participação ativa na roda observada); o bem-estar sentido ao frequentar a roda de TCI, principalmente pela oportunidade de desabafar e falar dos problemas; melhora em comportamento agressivo; benefício da desmedicalização e da criação das redes de apoio e a importância no respeito às diversidades que a roda proporciona.

As três rodas observadas apresentaram características distintas, em função do perfil de seus participantes. A roda de Vila Brasília é a com maior número de participantes e com participantes antigos, que já a frequentam há algum tempo. Os usuários possuem uma ótima relação com a médica da UBS, que inclusive faz a indicação para muitos participantes da roda. Acredita-se que o fato de a médica da Unidade de Saúde ser a Terapeuta Comunitária da Roda, facilite a adesão de muitos usuários. A roda de Volta Grande, estava com retorno recente, por isso a baixa frequência e com usuários ainda pouco adaptados a nova abordagem. A roda do Zoológico foi realizada provisoriamente no CAPS de Vila Cecília (local próximo ao original) e estava com frequência de usuários do CAPS e alunas estagiárias e professora da Disciplina de saúde Mental do curso de Técnica em Enfermagem. 
No PMS de 2014-2017 se vê o compromisso de garantir a TCI na Atenção Básica, por meio das Unidades de Atenção Básica e também nos serviços de Média Complexidade e nos de Saúde Mental.

No PMS de 2018 a 2021 permanece o compromisso de oferta da TCI nos Serviços de $\mathrm{AB}$ e média complexidade, além de fazer parte do PROJETO CENTRO DE PRÁTICAS INTEGRATIVAS, coadunando com a PNPIC de 2017, que incorporou a TCI no SUS (BRASIL, 2017).

No relatório da $10^{\circ}$ Conferência de Saúde de 2015, entre as propostas aprovadas estava a de garantir a TCI entre as Unidades de Saúde. Já no da $11^{\circ}$ Conferência, de 2017, como proposta para a rede de atenção à saúde estava a de Implantar Centro de Práticas Integrativas e Complementares e descentralizar o atendimento das Práticas Integrativas na Rede de Atenção à Saúde que referenciem os pacientes quando necessário.

\section{Discussão}

A implantação da TCI em Volta Redonda foi facilitada pelo momento político do país, que estava passando pelo segundo mandato do Presidente Luís Inácio Lula da Silva, do Partido dos Trabalhadores (PT), eleito pela primeira vez em 2002.

A TCI converge de forma importante com a ESF, dentro desta proposta de reorganização das práticas assistenciais e dos processos de trabalho, em substituição ao modelo clássico de atenção à saúde, entendido também como médico hegemônico, voltado para a consulta médica, individual. Entende também o usuário no seu contexto ampliado, considerando o conceito de família e os aspectos da promoção da saúde.

Com isso, a TCI desponta como uma tecnologia de trabalho, a qual as equipes da ESF podem se utilizar no cotidiano dos serviços e na comunidade, ao se depararem com o sofrimento difuso e enfrentarem a vulnerabilidade das condições de saúde mental das populações em situação de desvantagem econômica e social, abrindo espaço para a construção de redes solidárias

No município de Volta Redonda, o apoio da gestão central tanto na capacitação como no início da oferta das rodas, foi fundamental para o êxito da implantação.

A única barreira percebida para implantação pode ser vista como resistência comum da equipe de profissionais e dos usuários a uma nova proposta de trabalho, em particular com abordagem grupal. 
A resistência inicial dos usuários e profissionais a trabalhos grupais como a TCI, pode ser vista como uma característica atribuída à predominância de um modelo biomédico hegemônico que orienta as práticas de saúde, refletindo na expectativa por atendimento individual. Além desse fato, há um desconforto diante da equipe em trazer pra ESF uma nova técnica que auxilia na promoção da saúde mental, se apresentando como mais uma demanda de trabalho. A sobrecarga de trabalho pode ser vista como um ponto de resistência, já que a TCI precisa ser agregada às várias demandas profissionais. E a questão da TCI não exigir do terapeuta uma formação em nenhuma área acadêmica, pode trazer estranhamento e desconforto aos profissionais especializados da saúde mental.

No Município de Volta Redonda, a sensibilização aos profissionais e aos usuários nas Unidades e nos Conselhos de Saúde foi utilizada como estratégia de enfrentamento desta barreira, levando ao entendimento que a dificuldade foi apenas inicial, com pouca resistência a intervenção ao longo do tempo.

O contexto econômico e político do país mergulhou em uma instabilidade e crise a partir de 2014, no segundo mandato da Presidenta Dilma Roussef, também do partido dos trabalhadores (PT). A política de saúde entrou numa fase de indefinições e instabilidade com o agravamento da crise política em 2016, que culminou com o impeachment da presidente. Diante desse contexto, novas propostas foram lançadas vindo a desestabilizar ainda mais a base financeira do SUS e favorecer o fortalecimento dos mercados em saúde (MACHADO; LIMA; BAPTISTA, 2017).

Assim, após o momento inicial da implantação da TCI no município, pode-se identificar um segundo momento (a partir de 2015), ao que denominamos momento de intervenção, que também pode ser entendido como momento da implementação. Novas dificuldades foram verificadas pelos gestores para a continuidade da oferta. Com a troca de governo e consequente mudança de prioridades, algumas rodas foram sendo extintas e outras prioridades são colocadas para a saúde de seus usuários.

Com mudanças de governo no país, na gestão local e consequente mudanças na política, a partir de 2016, os profissionais capacitados em TCI no município de Volta Redonda foram sendo demitidos, juntamente com outros profissionais contratados pela prefeitura, pois não apresentavam vínculos empregatícios estáveis.

A questão das demissões em massa de funcionários com contratos terceirizados de trabalho na prefeitura, levando a redução da equipe de terapeutas comunitários, foi visto como uma barreira para continuidade da oferta inicial de rodas de TCI. Muitos entrevistados se remeteram a redução drástica da oferta de TCI no município devido a essas demissões, assim 
como ao clima de insegurança dos trabalhadores, tanto da gestão como da assistência. Além das demissões, os profissionais que ainda continuaram tiveram que fazer outras atividades e deixar de priorizar a roda de TCI.

Este cenário no município de Volta Redonda remonta a discussão sobre o processo de precarização do trabalho que vem ocorrendo no serviço público como um todo, com destaque aqui ao serviço público de saúde. A precarização do trabalho pode ser vista como a perda aos direitos trabalhistas ocorridas diante do mundo do trabalho e do retorno às ideias liberais de defesa do estado mínimo, surgidas nos países capitalistas desenvolvidos a partir da terceira década do século passado.

Foi percebido no estudo que muitos profissionais sem vínculo empregatício estável foram capacitados em terapia comunitária integrativa desde 2008, uma vez que se preferiu priorizar o perfil profissional e não o vínculo empregatício.

Pode-se dizer, que o fato de ainda hoje gestores com formação em TCI pertencerem a gestão, é visto como um ponto de resistência da oferta da intervenção. Porém, este fato também se apresenta como um risco para sua continuidade. Com uma mudança de gestão e política, esses mesmos profissionais, em um tempo futuro, podem não mais fazer parte da gestão, arriscando a continuidade da oferta atual.

Outro ponto de resistência da oferta da intervenção relatado por gestores e verificado nos documentos da Secretaria de saúde do município foi a presença de uma área técnica programática. Gestores argumentaram ser este um ponto de diferenciação de outras intervenções por esta ter um local, estar inserida no Programa de Práticas Integrativas e Complementares; este fato possibilita reunião periódica, discussão, onde o profissional - o terapeuta comunitário - tem um lugar para se dirigir e falar sobre a sua prática e dificuldades.

Com as observações às Rodas de TCI, pôde ser percebido que há um respeito aos recursos da estrutura da técnica, com local privativo e apropriado para grandes grupos. Os terapeutas comunitários respeitaram as etapas sem novas adaptações à técnica. Porém, a respeito do uso dos recursos culturais, foram pouco explorados, sendo utilizados somente na etapa do acolhimento.

Há algumas regras necessárias para o bom andamento da terapia: fazer silêncio, não dar conselhos, não julgar, falar de si (usar a primeira pessoa do singular), propor músicas, poemas, contos, história, fábula ou paródias que estejam relacionadas com o tema em questão.

De acordo com a regra das manifestações culturais, estas podem ser implementadas pelos terapeutas ou sugeridas pelos participantes em qualquer etapa da terapia. A implementação dos recursos culturais na TCI tem como objetivo uma maior participação da 
comunidade, integração entre os participantes, um melhor desenvolvimento das sessões bem como o fortalecimento de vínculo e resgate cultural. A música, por exemplo, com sua letra e som, tem a capacidade de acolhimento e permite compartilhar, nesta outra forma de linguagem, emoções, percepções e sensações que as vezes só com as palavras não damos conta (BARRETO, 2008; FIX; LEITE; GALVANI, 2007; OLIVEIRA; FERREIRA FILHA, 2011).

O local da Academia da Saúde foi visto como um local ideal para a oferta de TCI; não apenas pela sua estrutura física, mas principalmente por sua proposta. O Programa Academia da Saúde é uma estratégia de promoção e produção do cuidado com a saúde, a partir da implantação de espaços públicos, lançado pelo Ministério da Saúde em 2011 para os municípios brasileiros (BRASIL, 2011). O Programa adota uma concepção ampliada de saúde e estabelece como ponto de partida o reconhecimento do impacto social, econômico, político e cultural sobre a saúde. Por isso, apesar do nome, o Programa não se restringe a realização de práticas corporais e atividades físicas e promoção da alimentação saudável.

Apesar da oferta inicial de TCI ter diminuído, conforme relato dos entrevistados, os gestores consideraram que a oferta atual cobre três pontos estratégicos da cidade: As duas Academias da saúde, que dão acesso a duas partes distintas da cidade e o Zooológico Municipal, que está situado em uma área mais central. Eles consideram que o objetivo principal é que algumas áreas da cidade fiquem cobertas, independentemente do número de rodas; e também consideram que ter uma equipe mínima de três terapeutas (como foi realizado no início da implantação), exclusivos para a TCI, seria a melhor forma de cobrir os territórios da cidade, sem problemas de sobreposição de tarefas, sem acúmulo de função, como ocorre atualmente.

Em relação às Percepções sobre a efetividade da TCI, foi visto ao longo do estudo que a TCI cumpriu com seus principais objetivos (BARRETO, 2008). A visão dos entrevistados é que a TCI é uma técnica simples, porém potente, capaz de proporcionar a troca de experiências e estratégias de enfrentamento das dificuldades, do sofrimento, do adoecimento psíquico, possibilitando o fortalecimento das redes sociais de apoio, além da legitimação do conhecimento popular, produzido a partir das experiências de vida, resultando na restauração e no reforço da autoestima individual e do grupo. Sua importância foi também reconhecida para que cada indivíduo redescubra seus valores e potenciais, tornando-se mais autônomo e menos dependente.

Nas entrevistas, a maioria dos usuários colocou a oportunidade de redimensionar seus sofrimentos através da escuta de outras histórias de vida e contribuir para efetuar mudanças em suas vidas com vistas à sociabilidade. Os usuários tiveram a oportunidade de criar um espaço 
compartilhado de partilha de sofrimentos do cotidiano e o intercâmbio das experiências, transformando aquele espaço em parte importante das suas redes sociais.

A TCI pode ser considerada um instrumento de construção de redes sociais, como uma rede de apoio, solidária, trazendo suporte emocional, já que os participantes da roda se colocam em círculo para falarem de suas dificuldades e das respectivas estratégias de enfrentamento, possibilitando a partir daí a construção de novas redes. Nas entrevistas, foi percebido que nos locais onde a roda está implantada há mais tempo e sem interrupções (na Academia da Saúde de Nova Brasília e no Zoológico), os usuários se referiram a grupos de Whatsapp entre os participantes, inclusive com usuários que já não frequentam mais a roda, criando novas redes a partir da TCI.

Ainda sobre as percepções sobre a efetividade dos diferentes entrevistados, pôde ser visto o destaque no potencial da TCI na atenção as demandas de saúde mental como a redução da medicalização.

Medicalizar seria entendido como medicar, "cuidar-se por meio de medicamentos", ou também "exercer a medicina” (FREITAS; AMARANTE, 2017).

Há em nossa sociedade contemporânea uma exigência de um bem-estar constante, a crença de que toda forma de sofrimento e mal-estar deve ser evitado, remediado, onde as adversidades à existência devem ser evitadas. Vivemos em uma época caracterizada pela ideia de que "problemas mentais podem e devem ser tratados por drogas". Logo, a medicalização é uma resposta ao sofrimento, mesmo que muitas vezes seja uma resposta equivocada e com efeitos nocivos.

Percebemos atualmente como o tratamento farmacológico faz parte da vida cotidiana. O uso de psicotrópicos vai desde a regulação das mudanças de humor, melhora da performance no trabalho, como resistência a situações estressantes, à tristeza provocada pela perda e consequente luto, aos efeitos traumáticos de determinadas experiências, até ao tratamento das alterações associadas aos transtornos mentais graves.

\section{Considerações finais}

Os resultados deste estudo mostram a importância do contexto político ao longo do processo de implantação, ora facilitando-a, ora dificultando a manutenção da oferta da intervenção. As barreiras encontradas no momento inicial da implantação foram transponíveis ao longo do tempo. O sucesso da implantação e da permanência da oferta da intervenção na atenção básica do município de Volta Redonda foi determinado pelas estratégias adotadas pelos 
atores envolvidos na cena organizacional e por sua reação às barreiras encontradas ao longo dos 11 anos desde a implantação desta técnica grupal.

Com as diferentes mudanças no cenário da política do país e consequente mudanças no município, a oferta da técnica hoje se encontra reduzida a três pontos estratégicos da cidade, comparada ao início da implantação. Verificou-se que este fato não interferiu na qualidade da técnica oferecida, nem em seus benefícios. A presença de atuais gestores com formação em TCI, em conjunto com o engajamento social de usuários nos conselhos de saúde, intercedendo pela continuidade da oferta inicial apresentou importante papel de resistência dessa oferta; o que também pode ser visto como resultado dos benefícios trazidos pela roda de TCI no município.

Os benefícios trazidos pela técnica reforçam a política pública existente e que compreende uma diversidade em um contexto social abrangente. Outro fator é que o baixo custo, a alta efetividade e a busca de soluções participativas promovem uma política adequada no atendimento das diversas e complexas demandas presentes no contexto social.

Potencializar esse tipo de prática seria avançar na perspectiva da inclusão da saúde mental orientada para a (des)institucionalização na atenção básica em saúde. Pensar uma saúde mental para atenção básica é, sobretudo, valorizar uma perspectiva que busca compreender, aproximar e abordar o que acontece com as pessoas e entre as pessoas dentro de um território geográfico e subjetivo sempre em transformação.

Com base nos resultados obtidos, percebeu-se o quanto é importante avaliar as implantações dessa técnica em diferentes contextos, com vistas a dar seguimento a técnica e fortalecê-la em distintas realidades institucionais, além de contribuir para evidências científicas desta PIC na APS.

Vale ressaltar que a TCI foi vista como uma tecnologia de cuidado, em grupo, de baixo custo e com ações de promoção de saúde mental e prevenção do sofrimento emocional para as comunidades, além de possibilitar a inclusão social pela rede de apoio psicossocial que ela ajuda a construir, não deixando dúvidas quanto a sua legitimidade como instrumento de transformação.

\section{REFERÊNCIAS}

BARDIN, L. Análise de conteúdo. São Paulo: Edições 70, 2011.

BARRETO, A. P. Terapia comunitária: passo a passo. 3. ed. Fortaleza: Gráfica LCR, 2008. 
BRASIL. Ministério da Saúde. Portaria n. 971, de 03 de maio de 2006. Aprova a Política Nacional de Práticas Integrativas e complementares (PNPIC) no sistema Único de Saúde. Brasília: Ministério da Saúde, 2006. Disponível em:

https://bvsms.saude.gov.br/bvs/saudelegis/gm/2006/prt0971_03_05_2006.html. Acesso em: 15 jul. 2020.

BRASIL. Ministério da Saúde. Portaria n. 719, de 7 de abril de 2011. Institui o programa Academia da saúde no âmbito do Sistema Único de Saúde. Brasília: Ministério da Saúde, 2011. Disponível em:

https://bvsms.saude.gov.br/bvs/saudelegis/gm/2011/prt0719_07_04_2011.html. Acesso em: 15 jul. 2020.

BRASIL. Ministério da Saúde. Portaria n. 849, de 27 de março de 2017. Inclui a Arteterapia, Ayurveda, Biodança, Dança Circular, Meditação, Musicoterapia, Naturopatia, Osteopatia, Quiropraxia, Reflexoterapia, Reiki, Shantala, Terapia Comunitária Integrativa e Yoga à Política Nacional de Práticas Integrativas e Complementares. Brasília: Ministério da Saúde, 2017. Disponível em:

https://bvsms.saude.gov.br/bvs/saudelegis/gm/2017/prt0849_28_03_2017.html. Acesso em: 15 jul. 2020.

CHAMPAGNE, F. et al. A análise da implantação. In: Avaliação: conceitos e métodos. 1. ed. Rio de Janeiro: Editora Fiocruz, p. 217-238, 2011.

FIX, S. A. B.; LEITE, M. S. V.; GALVANI, C. Algumas reflexões sobre a inserção de música em encontros de TC no Centro de Assistência a Família (CEAF). In: Congresso Brasileiro de Terapia Comunitária, 3., 2007, São Paulo. Anais [...]. São Paulo: Casa do psicólogo/ABRATECOM, p. 451-457, 2007.

FONSECA, M. L. G.; GUIMARÃES, M. B. L.; VASCONCELOS, E. M. Sofrimento Difuso e Transtornos mentais Comuns: Uma revisão Bibliográfica. Rev. APS, v. 11, n. 3, p. 285-294, set. 2008 .

FREITAS, F.; AMARANTE, P. Medicalização em psiquiatria. Rio de Janeiro: Editora Fiocruz, 2017.

IBGE. Instituto Brasileiro de Geografia e Estatística. Censo demográfico. 2010.

MACHADO, C. V.; LIMA, L. D.; BAPTISTA, T. W. F. Políticas de saúde no Brasil em tempos contraditórios: caminhos e tropeços na construção de um sistema universal. Cadernos de Saúde Pública, v. 33, n. suppl. 2, 2 out. 2017.

MAGALHÃES, M. G. et al. Estratégias tecnoassistenciais do SUS- Volta Redonda. In: Tecendo redes: os planos da educação, cuidado e gestão na construcão do SUS: a experiência de Volta Redonda (RJ). Saúde em debate. São Paulo: Hucitec Editora, p. 25-42, 2012.

OLIVEIRA, D. S. T.; FERREIRA FILHA, M. O. Contribuição dos recursos culturais para a Terapia Comunitária Integrativa na visão do terapeuta. Rev Lat Am Enfermagem, v. 32, n. 3, p. 524-530, set. 2011. 
PINTO, S. et al. (Eds.). Tecendo redes: os planos da educação, cuidado e gestão na construcão do SUS: a experiência de Volta Redonda (RJ). São Paulo: Hucitec Editora, 2012.

VALLA, V. V. Globalização e saúde no Brasil: a busca da sobrevivência pelas classes populares via questão religiosa. In: A saúde nas palavras e nos gestos: reflexões da rede de educação popular e saúde. Saúde em debate. São Paulo: Editora Hucitec, p. 39-62, 2001.

\section{Como referenciar este artigo}

MACEDO, E.; LUIZA, V. L. FROSSARD, V. C. A Implantação da Terapia Comunitária Integrativa em um município do Rio de Janeiro. Temas em Educ. e Saúde, Araraquara, v. 16, n. esp. 1, p. 376-392, set., 2020. e-ISSN 2526-3471. DOI: https://doi.org/10.26673/tes.v16iesp.1.14318

Submetido em: 20/05/2020

Revisões requeridas: $30 / 05 / 2020$

Aprovado em: 25/08/2020

Publicado em: 30/09/2020 